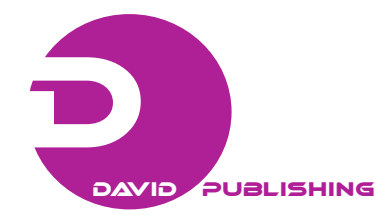

\title{
Nature’s Interactions with Culture, City, Female, and Beyond in "A White Heron”
}

\author{
Liang Ying \\ Beijing Foreign Studies University, Beijing, China
}

\begin{abstract}
What best distinguishes Sarah Jewett's regionalist writing is that she creates hybrid landscapes on which nature and culture merge, overlap, and collide. Even though nature in her "A White Heron” is concentrated into one abstract and powerful force, this study is about reading nature's different interactions with other concepts in the story and examines how the distinctions between nature and culture, nature and city, nature and female, and nature and beyond, are clearly maintained and yet how some boundaries of these are blurred or transcended. Accordingly, Jewett uses Maine landscapes and characters to frame universal questions of life and death, love and sexuality, permanence and change, and uses something small to symbolize larger issues of life. In the best of this regionalist writing, people see a focus on a particular area or group, but also a focus that enables the writer to find universal truths in very specific locales.
\end{abstract}

Key words: nature; culture; city; female; local

\section{Introduction}

Regionalism springs from an intimate relationship with and a sense of place to the natural environment. Thus regionalists' works get soaked in locality. Sarah Orne Jewett has long been associated with regionalism. Most of her stories are set in New England, often in southern Maine, where she was raised in middle class comfort. Reflecting her sensitivity to the people and places of Maine both past and present, is the strength of her best writing.

The story "A White Heron" has been examined more than any other single story of hers and has been treated a kind of "rebus" in which each critic reads his or her own message (Alaimo, 2000, p. 154). This study is about reading nature's different interactions with other concepts in the story and examines how the distinctions between nature and culture, nature and city, nature and female, and nature and beyond, are clearly maintained and yet how some boundaries of these are blurred or transcended.

Major characters of the story are: an adolescent girl, Sylvia, her grandma, Mrs Tilley, and a young man, an intruder and an ornithologist. Sylvia and her grandma live on an isolated farm deep in the Maine woods. Formerly living in a "crowded manufacturing town" (p. 459) and having a "solitary childhood self" (Blanchard, 1994, p. 171), Sylvia seeks the company of wild creatures and makes friends with animals. Grandma says she is "afraid of folks" (p. 459) and because of this fear of people, she has such intense communion with nature. The

Liang Ying, PhD, Associate Professor, Beijing Foreign Studies University.

Correspondence concerning this article should be addressed to Graduate School of Translation and Interpretation, Beijing Foreign Studies University, Beijing, 100089, China. Email: yingliang26@163.com. 
ornithologist comes to the farm and wants to kill and stuff a white heron, which is a rare bird, and add it to his collection. Sylvia knows the location of the nest of the white heron. Returning home after climbing the massive pine and experiencing a transformation that links her even more firmly with nature, Sylvia refuses to tell the hunter where the heron nests. She refuses to give away the bird's life (and her own) to a man. It is a painful choice because she is rejecting the money, man, culture, science, technology, city, heterosexuality, and the "great world" beyond rural New England. Her loyalty to nature is just too strong.

The ornithologist's quest for trophies represents the same impulse that drives male explorers in general to penetrate to the interiors of continents, "innocently" in search of scientific knowledge, simultaneously map the way to exploitable resources. As travelers, they fall on the negative side of a series of related dichotomies that Jewett's story makes clear. If the hunter / ornithologist represent culture, city, maleness, violence, then Sylvia may be said to stand in obvious opposition, representing nature, countryside, femaleness, harmony (Meisenheimer, 1997, p.112).

Jewett engages these key dichotomies but transcends them and narrates hybrid spaces also.

\section{Nature and Culture}

Compared to Sylvia's communion with nature, there is the ornithologist's relationship, which gives people conventional masculine terms. Literally bringing the machine into the garden, he masters the natural world through technology, shooting the birds with his gun. Then he forcibly transforms their fragile, decaying bodies into the permanent, if lifeless, figures of his collection. Finally, he brings abstract rational order to bear on the apparently random flux of nature through his ornithological categories. Now he is in quest of a small white heron, rarely seen in their region.

Jewett is sensitive to the questions of social class and social distinctions. The house where Sylvia and grandma live in the woods "stands on the periphery of civilization and mediates between nature and culture, as pastoral settings always have” (Sherman, 1989, p. 156). Sylvia is working class, shy and faltering, has undeveloped social skills and has grown "afraid of folks". "In addition to a formidable arsenal that includes scientific knowledge and technological mastery, the young man has money, the power to transform tangible realities into commodities quantified and suitable for exchange” (Sherman, 1989, p.156). The story also reveals the cruelty in the scientific quest for knowledge. The ornithologist offers Sylvia \$ 10 for the location of a white heron's nest although Sylvia sides with the heron, giving up the extraordinary sum of money.

Life exists in its potential and unceasing movement. The story focuses on an archetypal adolescent girl and the subtle transformations of her psychology and her relationships with people close at hand: unconsummated new friendships with males outside the family and attachments to older and more familiar adults within, and the fear of loss of innocence, etc. The associations of "female freedom with the expansive natural world" (Alaimo, 2000, p. 41) are spelled out here.

In the last scene, Sylvia makes a brief outing in the night, while her grandmother and the stranger are asleep. The dichotomy between "being asleep" and having "dream” versus "being awakened” runs through the whole story not only literally but also metaphorically. In this final scene, the stranger wakes from a dream, which is pretty ironic in that his dream of hunting the heron is actually about to be shattered and yet he is unaware of it, since he is sure that Sylvia "now must really be made to tell" (p. 465). Grandma, whose "long slumbering hospitality seemed to be easily awakened” (p. 460), also wakes up after the sleep. These two people who just wake up "stand in the door together [my emphasis] and question" (p. 465) Sylvia, which makes the occasion and the choice all the more difficult for Sylvia. 
Thus this story can be read as bildungsroman and people can trace the steps by which the heroine's self unfolds: her separation (in thrushes, her climbing the tree), testing, and realization (Alaimo, 2000, p. 154).This genre sometimes follows the tendency of women writers to "kill off their heroines' mothers as a strategy to give their fictional daughters open horizons" (Alaimo, 2000, p. 120). “A White Heron” is one and Their Eyes are Watching God is another example.

Jewett doesn't really probe generational misunderstandings and communication gaps like lots of women writers of her time do. Grandma is "a mild and unimaginative soul” (Blanchard, 1994, p. 172). In the last act of the story, grandma discovers the empty bed and the young hunter wakens, hoping he can persuade the shy little girl to tell where the nest is. Grandma neither fulfills the role of moral exemplar nor protector here.

Yet does the girl grow? Yes, she becomes even more fully than what she was at the outset: a "country child" (p. 465), "a romantic figure that succeeds in escaping the trials of adulthood and history" (Meisenheimer, 1997, p. 112). Her epiphany and initiation are completed.

\section{Nature and City}

But integration with the region is not easy: She needs to overcome both the ornithologist's bribe and various other temptations first. In one way, this tale is a confrontation between country and city which can be read socially. The general theme is "preservation of rural innocence from the taint of city corruption" (Eakin, 1973, p. 213).

By the end of the Civil War, textile mills and a cannery had largely replaced agriculture, shipbuilding, and logging as the economic base of the community, and the arrival of French-Canadian and Irish immigrants brought ethnic diversity to the town. The stable, secure, and remote small town Jewett knew and loved as a child was experiencing the economic, technological, and demographical pressures that transformed America in her lifetime.

In America, cities have been important in the development even of the frontier, serving as symbols of the expanding race's conquest of natural, and human, obstacles. The distance between rural America and the cities stood as a reproof to the inhumane forces accompanying the advance of industrialization, urbanization, and modernization.

"The story is weighted as heavily as possible against the city" (Eakin, 1973, p. 213). Jewett even conceived a sense of her people as a moral community sitting in judgment on modern America. For reasons not yet fully studied, perhaps owning to modern urbanization, city people disdain country folk as childlike, naïve, guileless, foolish, stupid, impassive, and uneducable. For Jewett, however, being stupid, being agape before the world is a virtue, and at root it signifies intensity in living and deeper spiritual engagement, instead of blandness or dullness. This is pretty similar to Bakhtin theory decades later.

Jewett believes that there is moral superiority of country people and their image of life that she would celebrate in her rural literature is far less negative than the mirror picture people got from urban Americans. For instance, silence is not only seen as a refusal to join in literary polemics but also regarded as a state of blessedness, innocence, or even power.

Four times Sylvia keeps silent in the text and each time is far different. Use a feminist reading. Carrying a gun and full game bag, the stranger is a young hunter searching for a place to eat and spend the night. Approached among the thrushes, Sylvia is frightened into silence and trembling in the first encounter. "She did not dare to look at the tall young man, who carried a gun over his shoulder" (p. 460). When the stranger asks 
her name, "silence was more alarmed than before" (p. 460). His words embody power and the power quiets her. The child's hesitation to speak in his presence suggests that in the dominating medium of masculine language, a woman can't help but be hushed, like the very birds the hunter shoots down. As what people have mentioned, Sylvia has spent her early childhood in a "crowded manufacturing town", "noisy", alienating, exploitive, an explicit threat (Blanchard, 1994, p. 335), which is associated in her mind with a frightening experience involving a great red-faced boy who used to chase her (p. 460). Thus afraid of communication plays a part in here.

Also, the dumbness of the rustic before the city person can be understood partly as a social response, indicative of a social and cultural gap and even a relative power relationship. It is the humble folk's way of avoiding further discomfiting communication with their betters.

When her grandma asks her to answer the hunter's questions, she keeps "an awed silence” (460). Both of these two silences mentioned above are both instinctual and her social choice to either resist or use silence "as a renunciation of rhetorical power” (Curnutt, 1997, p. 115).

The third time is when the hunter offers \$ 10 , "Mrs. Tilley gave amazed attention to all this, but Sylvia still watched the toad, not divining, as she might have done at some calmer time”, and says nothing. Yet "no amount of thought that night, could decide how many wished — For treasures the ten dollars, so lightly spoken of, would buy” (p. 462). This silence is more like a listening strategy than a resistance: She isn't unimpressed at all.

Yet in the last act, Sylvia's silence is power itself. It withholds information and "her unwillingness to speak contrasts rhetorically to the narrator's exhortations in the final paragraph” (Curnutt, 1997, p. 115). People will analyze more about her last silence a few pages later.

Does this mean that country folk has moral superiority? Does this mean that the social liabilities of country folk are moral virtues? At least country people lead their lives that are vital: They need to be willing to go to extremes at the crucial, appropriate moment. Sylvia's moment to choose whether to tell the hunter the secret or not is such a moment.

But on the other hand, is it possible to not to succumb to big city charms, and remain independent and free? Sylvia's choice seems to say yes. But the story doesn't give people a complex view because it talks about country folk resisting change, instead of adapting to change. Therefore people don't know what their girl could do after saying "no" to a change. For a historicist it is difficult to project Sylvia's victory over the noisy urban intruder. In the character of a little girl, the repercussions are less than obvious; it is only when her happy ending is applied to an older protagonist, an adult woman, that it seems especially problematic. The sacrifices of the regionalist or regionalist body begin to appear (Meisenheimer, 1997, p. 114).

Despite her hard-won integrity her isolation from human companionship at the story's close remains troubling. Since she reacts defensively against the American city, she may be estranged forever. Pick any passage about the land subject to being raped by human beings in Faulkner's "The Bear”, it shatters Sylvia's illusion of peacefully pastoral life. While she has found compensation in the landscape with its wild creatures, she still remains outside society, although the writer sees no evidence that she will lose what she has learned from that climb, from the communion with the heron.

\section{Nature and the Female Individual}

Sylvia was not born in nature, but introduced to its lore at a later age. She comes from an unnamed city, a 
manufacturing center. But she is part of nature, in communion, and nurture with nature and enjoys the world of nature and the gay freedom of childhood. Her name is "woods" in Latin. Birds in particular seem tame in her presence and she'd scanted herself of her own meals to have plenty to throw out amongst them if the grandmother had not prevented it.

Adopted by her widowed grandmother, she finds a new home on the very boundary of civilization. Their tiny house is entirely surrounded by woods. Her response to this pastoral setting is a burst of growth and bloom. But her great love is not the tidy cottage but the woods themselves. "A little maid who had tried to grow for 8 years in a crowded manufacturing town, but, as for Sylvia herself, it seemed as if she never had been alive at all before she came to live at the farm” (p. 459).

As the story opens at twilight, she is lazily driving home a loitering cow, Mistress Mooly, which is "plodding dilatory, provoking creature in her behavior, but a valued companion for all that. They were going away from whatever light there was, and striking deep into the woods, but their feet were familiar with the path, and it was no matter whether their eyes could see it or not” (p. 459).

Nature in the story is concentrated into one abstract and powerful force. People can even further rarify it into a virginal existence. Jewett creates humanized, if not romanticized nature, conjuring up an atmosphere of rural comfort and familiarity. The aim is to create a love for nature in the reader, out of sympathy for the little girl, who herself is identified with it.

In the last act, she is still and all the more a "country child" (p. 465). "Her body and body of the heron she pursues and the tree (pine) finally become metonymically linked” (Meisenheimer, 1997, p. 111) and share some common identity. Both she and the tree are described as birds "The murmur of the pine's green branches is in her ears, she remembers how the white heron came flying through the golden air and how they watched the sea and the morning together, and Sylvia can't speak; she can't tell the heron's secret and give its life away" (p. 465). There is a bodily identification with nature and Sylvia becomes the woods. She may also have taken power from the heron or at least benefits from a linkage between body and nature.

The associations of birds with the soul and with spirituality are ancient. The flight of birds, their freedom from the earth's pull, has made them the appropriate sign of human transcendence. Here, in her communion with the white heron she has come into possession of a higher loyalty, which she will not sell out to the vain world. She reaffirms her original communion with nature, but she does so conscious of her choice, and her rejection / loss (Sherman, 1989, p. 160).

Some critics dismiss local color writing as a less serious form of realism because they understand it as exploiting stereotypes and representing only the surface aspects of a region. Indeed, some local color writers operated in this manner. Yet focusing closely on the lives of people in a particular locale, a specific town, allows ambitious writers to create moving portraits of characters affected by their environment, especially women characters. More important, such portraits of rural life offered the chance for real social change since they often depicted the poor and disenfranchised. (Inness, 1997, pp. 3-4)

Sylvia is such a wonderful creation.

Women's relationship to nature is a universally signature theme and in the story Sylvia and her grandma live in a female world on this land. This is a nuclear family. Relations in it are based on love and mutual caring, seldom authority; so each member is precious.

As observed by Delbanco (1997), there is "a universal disjunction between the limitless human imagination and the constrictions within which all human beings live their lives” (p. 206). Yet to be a self, to define oneself as a subject with an independent inner life, was, to quote Emerson, the goal of human 
consciousness. Innocent and unsocialized, and starved for affection, she breaks out of her restricted world and "determines to win the friendship of the hunter by discovering the nest of the prized bird which he seeks" (Eakin, 1973, p. 213). The night, urged on by her desire to be recognized by the hunter and by the glory of the promised $\$ 10$, she breaks out of the house before dawn to search for the heron alone.

This leads to the topic that the story can also be seen as about the danger of losing virginity. In fact, there are quite some sexual innuendoes in the story, such as the image of an aggressive intruder "who carried a gun over his shoulder” (p. 460) and the mentioning of Sylvia’s "heart is thrilled by a dream of love” (p. 462).

The hunter is not bad: He speaks in a "cheerful and persuasive tone" (p. 460), always kind and gallant. He listens to Mrs. Tilley as she tells him about her four children and her vagabond son. She tells him of her remarkable sympathy for the wild creatures, how at home she is in the woods. The guest is suddenly interested, for he is "making a collection of birds myself" (p. 460). "I have been at it ever since I was a boy". Mrs. Tilley "smiled". This is a lovely Jewett touch (p. 461). He even interrupts the old woman, twisting the conversation to discover whether Sylvia can help him track the elusive bird. It is he who frightens Sylvia into an "awed silence" (p. 460), but such an exploitive man is still basically harmless (Blanchard, 1994, p. 360) in here. For instance, people don't know the consequences and the harm he brings to the farm if he doesn't get the heron.

The story is a realistic fiction in that the critical moment arrives and Sylvia is to decide whether or not to tell the stranger where to find the heron. In literary works, the painful self-searching, self-recognition, or self-creation is one of the most dramatic themes. To the hunter it is a splendid moment because this has been his dream for a long time; to grandma it is a rewarding moment because her hospitality is going to be paid back, yet to Sylvia it is a difficult moment.

She will not speak, though the temptation is great. The choice is clear. Loyalty to the young man would bring companionship but also submission to another's lead, a taming of her spirit and an acceptance of values not her own. Her loyalty to those values loses her the "great world", but in compensation it gives her communion with the natural world.

Sylvia chooses to "keep silence" (p. 465). This is because she realizes that she is in one with the natural world and she can't give a bird's life away for money. (Sylvia still lives in the regionalism in the late $19^{\text {th }}$ century; whereas the stranger lives in naturalism). Therefore in this final act, the stranger and grandma are actually still "sound asleep" (p. 465) though they are awake literally. The final scene also retouches the title of the story since in western tradition, white is usually associated with purity and innocence, the things of which Sylvia struggles and eventually succeeds to keep.

In the time Jewett wrote, realism as a genre was already well in shape. Sylvia, after careful deliberations, chooses not to take the easy roads. Like the scene in Huck Finn, this kind of episodes are always touching for many reasons, one of which could be, according to Faulkner, "the human heart in conflict with itself" is the only thing worth to be written about. In each of these scenes, the characters choose "a less trodden road" and this makes all the difference.

\section{Nature and Beyond}

If nature in the story is concentrated into one abstract and powerful force, does Jewett simplify social reality then? What is the literary mode of this piece: legend or mimetic work? Although she insists that Sylvia and her grandma are poor, there isn't any description of hard labor of country life, rural toil, or sweat that relies on strong arms. The work is comfortingly repeated. Human labor is virtually incorporated into nature. They 
take pleasure and pride in their daily routines. It is idyllic in mood and setting.

Does Jewett recreate the Maine she has known to recast it romantically and idealistically then? Does the story "express her nostalgia for the past of a rapidly changing New England?” (Westbrook, 1997, p. 276) In fact, the white heron itself verges on extinction, giving Jewett's tone in this story as well an elegiac quality. The huge pine Sylvia climbs is perhaps based on a tree long since felled (Meisenheimer, 1997, p. 122). The stories melt into the land and the life of the land until they are not stories at all, but life itself.

Or instead of "elements of fairy tale" (Roman, 1992, p. 55), her story is more in the realistic tradition since she does reach the realistic maturity in this piece. She is to press a point about rural American mores, use it to critique American society or to combine the two genres, let people see their modern and complex problems mirrored in a simpler and more primitive world. (The latter is what Cleanth Brooks defined as pastoral).

Could her urban readers transcend their own moral sensibilities and see life from the point of view of the country folk? Yet in calling for a shucking off of urban pretensions, she does not necessarily imply either that country folk has a mystical or transcendental understanding of life and death. So maybe Jewett is a romantic by persuasion and a realistic at heart. Jewett is known for finely crafted, lyrical stories that often engage pressing social issues. Thus the perspectives people view her writings also need to transcend boundaries.

Regionalism, prizing the familiar and provincial, can clash with the modernist spirit. Yet Joyce, Woolf, and Faulkner wrote with a sense of place, even topographically, as they dissolved consciousness itself. Accordingly, Jewett uses Maine landscapes and characters to frame universal questions of life and death, love and sexuality, permanence and change, and uses something small to symbolize larger issues of life. In the best of this regionalist writing, people see a focus on a particular area or group, but also, much like they find in Twain, Chopin, or Faulkner, a focus that enables the writer to find universal truths in very specific locales. Faulkner said in his Nobel Prize acceptance speech: “Truth is one. It doesn't change. It covers all things which touch the heart — honor and pride and pity and justice and courage and love. Do you see it now?”

Yes, they do, only when they take care of both the breadth and depth very well.

\section{References}

Alaimo, Stacy. (2000). Undomesticated Ground: Recasting Nature as Feminist Space. Ithaca: Cornell University Press.

Blanchard, Paula. (1994). Sarah Orne Jewett: Her World and Her Work. Mass: Radcliffe.

Curnutt, Kirk. (1997). Wise Economies: Brevity and Storytelling in American Short Stories. Moscow, Idaho: University of Idaho Press.

Delbanco, Andrew. (1997). Required Reading: Why Our American Classics Matter Now? New York: Farr, Straus and Giroux.

Eakin, Paul John. (1973). Sarah Orne Jewett and the Meaning of Country Life. Richard Cary. (Ed.), Appreciation of Sarah Orne Jewett: 29 Interpretive Essays. (pp. 203-222). Waterville, Maine: Colby College Press.

Inness, Sherrie A., \& Diana Royer. (1997). Intro. Breaking Boundaries: New Perspectives on Women's Regional Writing. Sherrie A. Inness., \& Diana Royer. (Eds.), Iowa City: University of Iowa Press, 1997.

Lamb, Bob. (Ed.), (2003). American Literature Survey from 1865 to the Present. (pp. 458-465). West Lafayette, IN: Purdue University.

McQuade, Donald et al., (Eds.), (1987). The Harper American Literature. Vol.2. New York: Harper \& Row Publishers.

Meisenheimer, D. K. Jr. (1997). Regionalist Bodies / Embodied Regions: Sarah Orne Jewett and Zitkala-Sa. Sherrie A. Inness., \& Diana Royer. (Eds.), Breaking Boundaries: New Perspectives on Women’s Regional Writing. (pp. 109-124). Iowa City: University of Iowa Press.

Roman, Margaret. (1992). Sarah Orne Jewett: Reconstructing Gender. Tuscaloosa: The University of Alabama Press. Sherman, Sarah Way. (1989). Sarah Orne Jewett, An American Perspective. Hanover: University Press of New England. Westbrook, Perry D. (1997). Sarah Orne Jewett. Denise D. Knight., \& Emmanuel S. Nelson. (Eds.), 19 ${ }^{\text {th }}$ Century American Women Writers: A Bio-Bibliographical Critical Sourcebook. (pp. 270-280). Westport: Connecticut: Greenwood Press. 